\title{
PREGNANCY RELATED TO ANXIETY AMONG CHRONICALLY ILL WOMEN ${ }^{1}$ Wafaa Elsayed Hamed Mohamed, ${ }^{2}$ Amina Mohamed Rashad Elnemer
}

1 Bsc nursing, Faculty of Nursing Mansoura University, Egypt

2 Professor of women's health and midwifery nursing, Faculty of Nursing Mansoura University, Egypt E- mail of corresponding Author,wafaaelzaky@gmail.com

\begin{abstract}
Pregnancy is a time of great joy, excitement and anticipation for most women. Unfortunately, for many it can also be a time of serious problem, even for women who have never had problems. Chronic diseases represent a major problem and public health burden in developing countries. It represents $73.0 \%$ of mortality and $60.0 \%$ of global morbidity burden. In Egypt about $26.0 \%$ of all deaths related to chronic diseases. Its risk comes higher during pregnancy. Aim: the current study aimed to describe pregnancy related anxiety among chronically ill women. Design: Descriptive research design was used to achieve the aim of this study. Setting: This study was conducted at antenatal outpatient unit at Mansoura University Hospital in Mansoura city over a period of five months started on July 2017 \& finished on November 2017. Subjects: A purposive sample was used to select sixty five pregnant women with chronic illness. Tools: two tools were used for data collection; the first tool was Structured Interviewing Questionnaire. General characteristics, the past and present Obstetrical history, and the chronic condition during pregnancy. Tool two was Pregnancy-Related Anxiety Questionnaire-Revised (PRAQ-R2). The PRAQ-R2 is composed of 11 items that are used to assess and identify pregnancy-specific anxiety in nulliparous and parous women. Results Slightly more than half of the women have DM. Nearly half of them experienced severe anxiety. More than two fifth of the studied women reported that they were afraid of giving birth. More than half of them were severely worries about bearing handicapped child, more than two fifths of them severely concerned by their own appearance. There were a highly significant relation between the anxiety level according to PRAQ-R2 and its three sub domains, number of children, level of education of the women, gestational age and women's duration of illness. Recommendations: Simple handouts as booklets and brochures about chronic diseases and anxiety pattern should be developed and distributed at antenatal clinics. Evidence-based anxiety and chronic disease care guidelines should be integrated in maternity courses curriculum for nursing students. Finally, anxiety management enhancing educational session should be applied at the maternity hospitals and centers .for health care provider
\end{abstract}

Key words: Pregnant, chronic illness, anxiety, women health

\section{Introduction:}

Chronic illnesses are a major problem and public health burden in developing countries. It responsible for $73.0 \%$ of mortality and $60.0 \%$ of global morbidity burden. There is emerging evidence that diabetes mellitus, obesity, hypertension, contribute to national morbidity \& mortality in Egypt as it represents about $26.0 \%$ of all deaths related to chronic illnesses (Centers for Disease Control and Prevention (CDC), 2017).

Chronic diseases are responsible for a lot of complication during pregnancy which may last after delivery, so women with chronic diseases are often anxious about pregnancy. but, due to medical progress and detailed pregnancy planning 
in collaboration with specialists, so women with chronic diseases have chance to become pregnant . For instance, 100 years ago, women with multiple sclerosis were advised against pregnancy; however, in subsequent decades, studies demonstrated that this disease may enter into temporary remission during pregnancy, and it is no longer considered a contraindication (Kersten et al., 2014).

Maternal health complications during pregnancy have been shown to impact later offspring weight and growth patterns. Gestational hypertension as well as gestational diabetes has been linked to an increased risk of high birth weight and large size for gestational age, both of which have been shown to predict subsequent childhood overweight and obesity (Anam, 2013).

Maternity nurse plays an important role in antenatal care especially in managing chronic illness and anxiety. This role includes; relevant assessment, planning, implementation and evaluation of care provided. They teach the expectant mothers how to control and deal with anxiety, and improve their compliance for medication and care.

\section{Significance of the study}

Pregnancy is a period of great joy for many women, but also one of great stress both physically and mentally. Even in healthy women, pregnancy may give rise to many anxieties because of expected uncertainty associated with it. Evidences show that anxiety during pregnancy not only affects on the health of mother but also have an impact on labor outcomes as preterm delivery, prolonged labor, increase the rate of caesarean birth, low birth weight (Madhavanprabhakaran, 2015).

Chronic conditions such as diabetes, hypertension, and kidney disease can have adverse impact on pregnant woman such as gestational hypertension, preeclampsia, and maternal mortality (Estensen et al., 2011; Josephson \& McKay, 2011). In addition, chronic illness can have adverse outcomes on infants, including preterm births, intrauterine growth restriction, and neonatal mortality (Parkes, Schenker, \& Shufaro, 2013).

Managing chronic illness may be altered by pregnancy and cause more stress and anxiety Understanding the effects of chronic disease on pregnancy and associated symptoms is important to improve overall maternal and fetal wellbeing and family health. Comorbidities, whether chronic or pregnancy related, have been found to be significant contributors to near-miss situations that resulted in increased perinatal morbidity and mortality (Mhyre, Bateman, \& Leffert, 2011). Few studies in Egypt have focused on anxiety and chronic illness of the pregnant women, therefore this study conducted to describe pregnancy related anxiety among chronic ill women.

\section{Aim of the study}

The aim of this study is to describe pregnancy related anxiety among chronic ill women.

\section{Research question:}

Does a pregnant woman with chronic illness express anxiety?

\section{Subjects and Method Subjects Study Design:}

Descriptive research design was used to achieve the aim of this study.

\section{Study setting:}

This study was conducted at Antenatal outpatient unit at Mansoura University Hospital in Mansoura city

\section{Subjects of the study:}

The study subjects consisted of sixty five pregnant women with chronic illness who were attended to Antenatal outpatient unit at Mansoura University Hospital in Mansoura city. They were selected according to the following inclusion criteria. 
PREGNANCY RELATED TO ANXIETY AMONG etc...

Inclusion Criteria:

A. Women in child bearing period (18-45)

B. Pregnant women during third trimester

C. Women who have chronic disease (diabetes mellitus and hypertension).

Exclusion criteria:

A. Women who have psychological disorders as anxiety or depression because these two diseases are linked to adverse outcomes in pregnancy.

B. Women who have more than one chronic illness.

Sample type:

Sample size:

A Purposive sample was used.

The study includes sixty five pregnant women with chronic illness.

\section{Tools of data collection:}

\section{Tool I: Structured Interviewing} Questionnaire:

It was designed by the researcher after reviewing the related literature. It was consisted of three parts to measure the following:

Part1: It was used to assess the general characteristics includes (age, residency, occupation, duration of marriage educational level, and number of children).

Part 2: It was used to assess the past and present Obstetrical history includes history of current pregnancy such as (gestational age, number of fetus, complicated or not, type of complication)

Part 3: It was used to assess the chronic condition during pregnancy includes History of chronic disease such as (diagnosis, duration of illness, controlled or not, hospitalized or not, If yes, (numbers, days, intervention required), compliance with medication, drug used, and complications)

Tool II: Assessment of anxiety using: Pregnancy-Related Anxiety
Questionnaire-Revised

(PRAQ-R2)

(Huizink et al., 2016)

The 11-item Pregnancy-Related Anxiety Questionnaire-Revised (PRAQ$\mathrm{R} 2$ ) is a widely used instrument to assess and identify pregnancy-specific anxiety in nulliparous and parous women. It has good psychometric values and predictive validity for birth and childhood outcomes. The PRAQ-R was modified by Huizink et al 2016 and as they modify it to include 11 items instead of 10 items in order to be used with nulliparous and parous women, then it called PRAQ_R2. The PRAQ-R and PRAQ-R2 Cronbach's alphas across the total scale were good (above 0.80) and generally comparable. The PRAQ-R2 include the three subscales; Fear of giving birth (Items 1, 2, 6), Worries about bearing a physically or mentally handicapped child (Items 4, 9-11) and Concern about one's own appearance (Items 3, 5, 7)

The PRAQ_R2 is composed of 11 items that are combined to form 3 subscale; each of them has a range of 1-5 points. In all cases, score of (1) indicates never anxiety; while a score of (5) indicates

more anxiety. The 3 subscale are then added to yield one (total) score, with a range of (11-55) points, (11) indicates never anxiety and (55) indicate more anxiety. Levels of anxiety among the pregnant women are divided into three levels; mild, moderate, and sever based on quartiles classifications according to the following;

- $25^{\text {th }}$ quartile to less than $50^{\text {th }}$ quartile indicates mild anxiety.

- $50^{\text {th }}$ quartile to less than $75^{\text {th }}$ quartile indicates moderate anxiety.

- $75^{\text {th }}$ quartile and more indicates sever anxiety. 
Wafaa Elsayed Hamed Mohamed, \& Amina Mohamed Rashad Elnemer

Method

The Pilot Study:

was carried out at Antenatal outpatient unit at Mansoura University Hospital on $10 \%$ of the sample size (seven pregnant women) to test the applicability $\&$ relevance of the research tools $\&$ the clarity of the designed questionnaire and the required modification were made. The pilot sample was excluded from the study. Field Work:

The study was carried out in a period of eight months period beginning on July 2016 \& finished on February 2017 to gather the data required for assessment of anxiety and chronic illness.

\section{Data collection}

The researcher was visiting Antenatal outpatient unit at Mansoura University Hospital two days per week from 9 am - 1 $\mathrm{pm}$. The researcher introduced herself to pregnant women who are selected according to inclusion and exclusion criteria, took written consent of them to be included within the study after clarification of study aim. Then the researcher interviewed each woman individually for 20-25 minutes.

During the interview, the researcher read every item of the data collection sheet $\&$ clarified its meaning to the woman, and utilizing Pregnancy-Related Anxiety Questionnaire-Revised (PRAQ-R2) to assess anxiety associated with her chronic illness. Women were permitted to ask for any interpretation, elaboration or explanation. Finally, the researcher was informing each woman if she has any questions call the researcher telephone to answer them about.

\section{Statistical analysis:}

The collected data were coded and transferred into a specially designed format so as to be suitable for computer feeding. Following data entry, checking and verification process were carried out to avoid errors during data entry.
All statistical analyses were performed using SPSS for windows version 20.0 (SPSS, Chicago, IL). All data were categorical data and were expressed in number and percentage. Descriptive statistics as frequency, distribution, mean, and standard deviation were used to describe different characteristics. Pearson's chi-squared test was used for testing relationships between categorical variables. The Cronbach's alpha is used to assess the reliability (or internal consistency) of a set of subscale of the PRAQ. Statistical significance was set at $\mathrm{p}<0.05$.

\section{Ethical consideration:}

- An official permission will be taken from the head of Obstetrics and Gynecology department, Mansoura University Hospital to carry out this study after explanation of the aim and method of the study.

- An official approval will be taken from the Ethics Committee of the Faculty of Nursing, Mansoura University.

- Participation in the study is voluntary and each participant has the right to accept or refuse participation in the study.

- Confidentiality of the collected data will be maintained.

- The result will be used as a component of the necessary research for other studies as well as for future publications and education.

\section{Results}

Figure (1) portrays that, nearly half of the women experienced severe anxiety according to the total anxiety sum score either by old subscale (PRAQ-R) or new subscale (PRAQ-R2) scoring (46\% and $49 \%$ respectively.

Figure (2) presents that, more than two fifth of the studied women reported that they are afraid of giving birth with the same finding either by old 
subscale (PRAQ-R) or by new subscale (PRAQ-R2) findings (46\% for both).

Figure (3) portrays that more than half $(55 \%)$ of the women are severely worries about bearing handicapped child.

Figure (4) shows that, more than two fifths $(48 \%)$ of the women severely concerned by their own appearance.

Table (1) portrays that there is a highly significant relation between the Anxiety level according to PRAQ-R2 and its three subdomains; fear of giving birth, worries about bearing a handicapped child and concern about own appearance ( $p$ value is 0.000 for all of them).

Table (2) presents that there is a highly significant relation between the anxiety level according to PRAQ-R2 and number of children and level of education of the women ( $\mathrm{p}$ value is 0.000 for both).
Whereas, there is no significant relation observed between anxieties level according to PRAQ-R2 and women's age, place of residence and occupation.

Table (3) presents that there were highly significant relation between the anxiety level according to PRAQ-R2 and gestational age ( $\mathrm{p}$ value is 0.003). Whereas, there is no significant relation observed between anxiety level according to PRAQ-R2 and number of fetus.

Table (4) presents that there is no significant relation between the anxiety level according to PRAQ-R2 and diagnosis of the women. Whereas, there is a significant relation observed between anxieties level according to PRAQ-R2 and women's duration of illness with $p$ value (0.028).
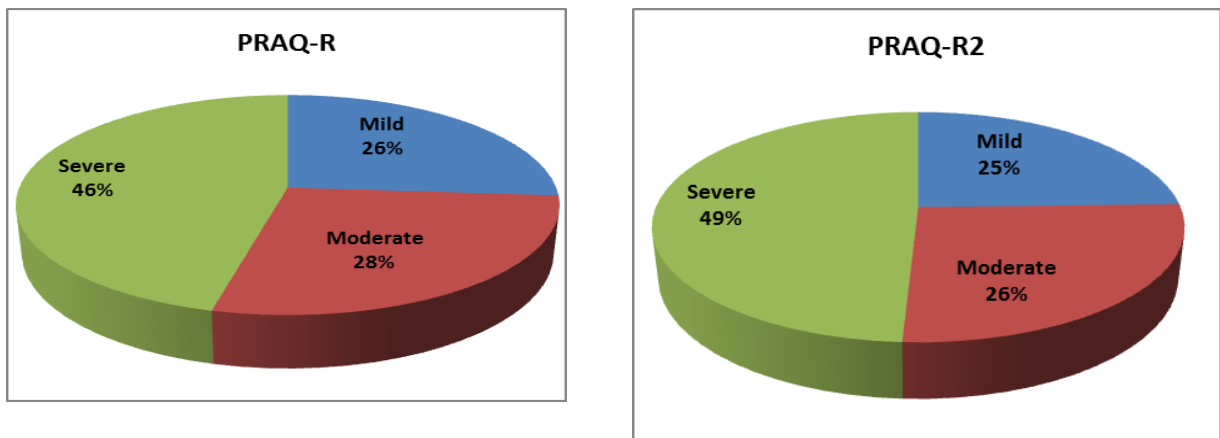

Figure (1) Distribution Of The Studied women According To Their Total Anxiety Sum Score using PRAQ-R and PRAQ_R2 $(n=65)$
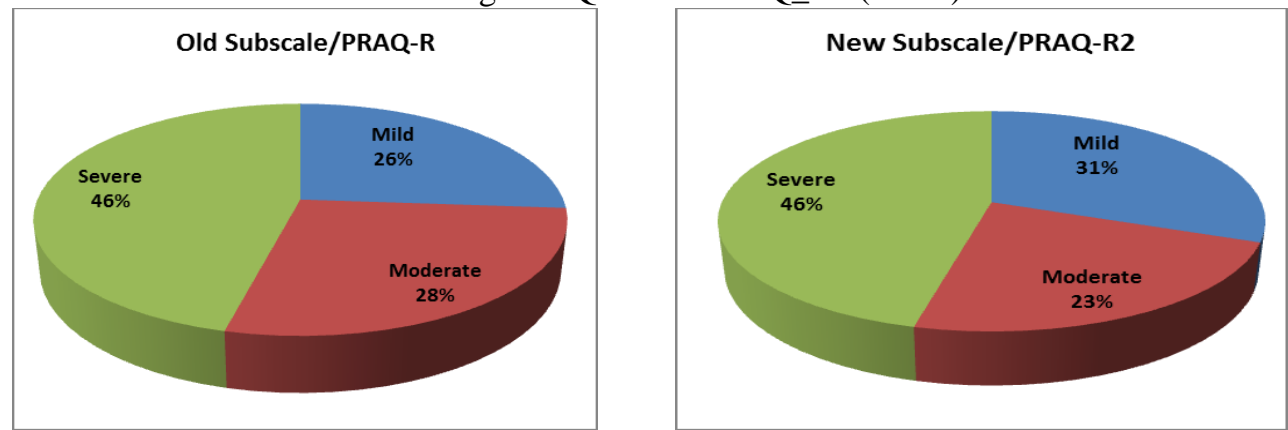

Figure (2) Distribution of the Studied women according To Their Fear of Giving Birth using PRAQ-R (Old Subscale) and PRAQ_R2 (New subscale) $(\mathrm{n}=65)$ 


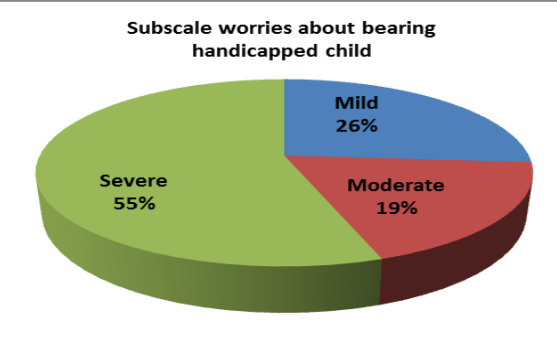

Figure (3) Distribution of the Studied women according To Their Subscale worries about bearing handicapped child $(n=65)$

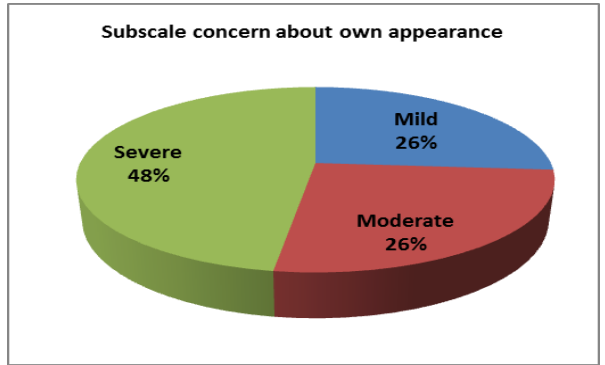

Figure (4) Distribution of the Study

Studied women according To Their Concern About Own Appearance $(n=65)$

Table (1) Distribution Of The Studied women According To The relationship between Anxiety level and its subscales) $(n=65)$

\begin{tabular}{|c|c|c|c|c|c|c|c|c|c|c|}
\hline \multirow{3}{*}{ Subscale } & \multicolumn{6}{|c|}{ Anxiety level according to PRAQ-R2 } & \multirow{2}{*}{\multicolumn{2}{|c|}{$\begin{array}{l}\text { Total } \\
n=65\end{array}$}} & \multirow{2}{*}{\multicolumn{2}{|c|}{$\begin{array}{c}\text { Test of } \\
\text { significance }\end{array}$}} \\
\hline & \multicolumn{2}{|c|}{$\begin{array}{l}\text { Mild } \\
n=16\end{array}$} & \multicolumn{2}{|c|}{$\begin{array}{c}\text { Moderate } \\
\mathbf{n}=17\end{array}$} & \multicolumn{2}{|c|}{$\begin{array}{c}\begin{array}{c}\text { Severe } \\
\mathrm{n}=32\end{array} \\
\end{array}$} & & & & \\
\hline & No & $\%$ & No & $\%$ & No & $\%$ & No & $\%$ & $\begin{array}{c}\text { Chi- } \\
\text { square }\end{array}$ & $\begin{array}{c}\mathbf{P} \\
\text { Value }\end{array}$ \\
\hline \multicolumn{11}{|c|}{$\begin{array}{l}\text { Fear of } \\
\text { giving birth }\end{array}$} \\
\hline Mild & 13 & 81.2 & 7 & 41.2 & 0 & 0.0 & 20 & 30.8 & \multirow[t]{3}{*}{40.015} & \multirow[t]{3}{*}{$0.000 *$} \\
\hline Moderate & 2 & 12.5 & 8 & 47.1 & 5 & 15.6 & 15 & 23.1 & & \\
\hline Severe & 1 & 6.2 & 2 & 11.8 & 27 & 84.4 & 30 & 46.2 & & \\
\hline \multicolumn{11}{|c|}{$\begin{array}{l}\text { Worries } \\
\text { about } \\
\text { bearing a } \\
\text { handicapped } \\
\text { child }\end{array}$} \\
\hline Mild & 15 & 93.8 & 2 & 11.8 & 0 & 0.0 & 17 & 26.2 & \multirow[t]{3}{*}{49.777} & \multirow[t]{3}{*}{$0.000 *$} \\
\hline Moderate & 1 & 6.2 & 9 & 52.9 & 2 & 6.2 & 12 & 18.5 & & \\
\hline Severe & 0 & 0.0 & 6 & 35.3 & 30 & 93.8 & 36 & 55.4 & & \\
\hline \multicolumn{11}{|c|}{$\begin{array}{l}\text { Concern } \\
\text { about own } \\
\text { appearance }\end{array}$} \\
\hline Mild & 11 & 68.8 & 6 & 35.3 & 0 & 0.0 & 17 & 26.2 & \multirow[t]{3}{*}{45.537} & \multirow[t]{3}{*}{$0.000 *$} \\
\hline Moderate & 5 & 31.2 & 10 & 58.8 & 2 & 6.2 & 17 & 26.2 & & \\
\hline Severe & 0 & 0.0 & 1 & 5.9 & 30 & 93.8 & 31 & 47.7 & & \\
\hline
\end{tabular}

* Significant $\mathrm{P} \leq \mathbf{0 . 0 5}$ 
PREGNANCY RELATED TO ANXIETY AMONG etc ...

Table (2) Distribution of the Studied women according To the Relationship between Anxiety level according to PRAQ-R2 And Their Socio-Demographic Characteristics $(n=65)$

\begin{tabular}{|c|c|c|c|c|c|c|c|c|c|c|}
\hline \multirow{3}{*}{$\begin{array}{l}\text { Socio- } \\
\text { demographic } \\
\text { data }\end{array}$} & \multicolumn{6}{|c|}{ Anxiety level according to PRAQ-R2 } & \multirow{2}{*}{\multicolumn{2}{|c|}{$\begin{array}{l}\text { Total } \\
n=65\end{array}$}} & \multirow{2}{*}{\multicolumn{2}{|c|}{$\begin{array}{l}\text { Test } \\
\text { significance }\end{array}$}} \\
\hline & \multicolumn{2}{|c|}{$\begin{array}{l}\text { Mild } \\
\mathrm{n}=16\end{array}$} & \multicolumn{2}{|c|}{$\begin{array}{l}\text { Moderate } \\
\mathrm{n}=\mathbf{1 7}\end{array}$} & \multicolumn{2}{|c|}{$\begin{array}{l}\text { Severe } \\
n=32\end{array}$} & & & & \\
\hline & No & $\%$ & No & $\%$ & No & $\%$ & No & $\%$ & $\begin{array}{l}\text { Chi- } \\
\text { square }\end{array}$ & P Value \\
\hline \multicolumn{11}{|l|}{ Age (Years) } \\
\hline 18 to 25 years & 3 & 18.8 & 5 & 29.4 & 14 & 43.8 & 22 & 33.8 & \multirow[t]{3}{*}{2.674} & \multirow[t]{3}{*}{0.071} \\
\hline 26 to 35 years & 7 & 43.8 & 4 & 23.5 & 10 & 31.2 & 21 & 32.3 & & \\
\hline 36 to 48 years & 6 & 37.5 & 8 & 47.1 & 8 & 25.0 & 22 & 33.8 & & \\
\hline \multicolumn{11}{|l|}{ Residence } \\
\hline Rural & 6 & 37.5 & 9 & 52.9 & 14 & 43.8 & 29 & 44.6 & \multirow[t]{2}{*}{0.067} & \multirow[t]{2}{*}{0.478} \\
\hline Urban & 10 & 62.5 & 8 & 47.1 & 18 & 56.2 & 36 & 55.4 & & \\
\hline \multicolumn{11}{|l|}{ Occupation } \\
\hline House wife & 4 & 25.0 & 8 & 47.1 & 11 & 34.4 & 23 & 35.4 & \multirow[t]{2}{*}{0.175} & \multirow[t]{2}{*}{0.414} \\
\hline Working & 12 & 75.0 & 9 & 52.9 & 21 & 65.6 & 42 & 64.6 & & \\
\hline \multicolumn{11}{|l|}{$\begin{array}{l}\text { Number of } \\
\text { children }\end{array}$} \\
\hline No children & 2 & 12.5 & 6 & 35.3 & 21 & 65.6 & 29 & 44.6 & \multirow[t]{3}{*}{13.251} & \multirow[t]{3}{*}{$0.000^{*}$} \\
\hline One & 6 & 37.5 & 5 & 29.4 & 7 & 21.9 & 18 & 27.7 & & \\
\hline More than one & 8 & 50.0 & 6 & 35.3 & 4 & 12.5 & 18 & 27.7 & & \\
\hline \multicolumn{11}{|l|}{ Educational Level } \\
\hline $\begin{array}{l}\text { Can't Read } \\
\text { and write. }\end{array}$ & 9 & 56.2 & 2 & 11.8 & 3 & 9.4 & 14 & 21.5 & \multirow[t]{3}{*}{15.903} & \multirow[t]{3}{*}{$0.000 *$} \\
\hline $\begin{array}{ll}\text { Primary } & \text { / } \\
\text { Secondary } \\
\text { school } \\
\text { graduate. }\end{array}$ & 5 & 31.2 & 4 & 23.5 & 6 & 18.8 & 15 & 23.1 & & \\
\hline $\begin{array}{l}\text { High school / } \\
\text { University } \\
\text { graduate }\end{array}$ & 2 & 12.5 & 11 & 64.7 & 23 & 71.9 & 36 & 55.4 & & \\
\hline
\end{tabular}

* Significant $\mathbf{P} \leq \mathbf{0 . 0 5}$

Table (3) Distribution of the Studied women according To the Relationship between Anxiety level according to PRAQ-R2 And Their History Of Current Pregnancy ( $n=65)$

\begin{tabular}{|c|c|c|c|c|c|c|c|c|c|c|}
\hline \multirow{3}{*}{$\begin{array}{c}\text { History } \\
\text { of current } \\
\text { pregnancy }\end{array}$} & \multicolumn{6}{|c|}{ Anxiety level according to PRAQ-R2 } & \multirow{2}{*}{\multicolumn{2}{|c|}{$\begin{array}{l}\text { Total } \\
n=65\end{array}$}} & \multirow{2}{*}{\multicolumn{2}{|c|}{$\begin{array}{c}\text { Test of } \\
\text { significance }\end{array}$}} \\
\hline & \multicolumn{2}{|c|}{$\begin{array}{l}\text { Mild } \\
n=16\end{array}$} & \multicolumn{2}{|c|}{$\begin{array}{c}\begin{array}{c}\text { Moderate } \\
\mathbf{n}=17\end{array} \\
\end{array}$} & \multicolumn{2}{|c|}{$\begin{array}{c}\begin{array}{c}\text { Severe } \\
\mathbf{n}=\mathbf{3 2}\end{array} \\
\end{array}$} & & & & \\
\hline & No & $\%$ & No & $\%$ & No & $\%$ & No & $\%$ & $\begin{array}{c}\text { Chi- } \\
\text { square }\end{array}$ & $\begin{array}{c}\mathbf{P} \\
\text { Value }\end{array}$ \\
\hline Gestational age & & & & & & & & & & \\
\hline $\begin{array}{l}24 \text { to } 32 \\
\text { week }\end{array}$ & 11 & 68.8 & 10 & 58.8 & 8 & 25.0 & 29 & 44.6 & 9.296 & $0.003 *$ \\
\hline $\begin{array}{l}32 \text { to } 40 \\
\text { week }\end{array}$ & 5 & 31.2 & 7 & 41.2 & 24 & 75.0 & 36 & 55.4 & & \\
\hline $\begin{array}{l}\text { Number of } \\
\text { fetus }\end{array}$ & & & & & & & & & & \\
\hline Single & 12 & 75.0 & 14 & 82.4 & 20 & 62.5 & 46 & 70.8 & 0.639 & 0.273 \\
\hline Double & 4 & 25 & 3 & 17.6 & 12 & 37.5 & 19 & 29.2 & & \\
\hline
\end{tabular}

* Significant $\mathrm{P} \leq \mathbf{0 . 0 5}$ 
Table (4) Distribution of the Studied women according To the Relationship between Anxiety level according to PRAQ-R2And Their History Of Chronic Diseases $(n=65)$

\begin{tabular}{|c|c|c|c|c|c|c|c|c|c|c|}
\hline \multirow{3}{*}{$\begin{array}{c}\text { History of } \\
\text { chronic disease }\end{array}$} & \multicolumn{6}{|c|}{ Anxiety level according to PRAQ-R2 } & \multirow{2}{*}{\multicolumn{2}{|c|}{$\begin{array}{l}\text { Total } \\
n=65\end{array}$}} & \multirow{2}{*}{\multicolumn{2}{|c|}{$\begin{array}{c}\text { Test of } \\
\text { significance }\end{array}$}} \\
\hline & \multicolumn{2}{|c|}{$\begin{array}{l}\text { Mild } \\
\mathrm{n}=16\end{array}$} & \multicolumn{2}{|c|}{$\begin{array}{c}\text { Moderate } \\
\mathbf{n}=17\end{array}$} & \multicolumn{2}{|c|}{$\begin{array}{c}\begin{array}{c}\text { Severe } \\
n=32\end{array} \\
\end{array}$} & & & & \\
\hline & No & $\%$ & No & $\%$ & No & $\%$ & No & $\%$ & $\begin{array}{c}\text { Chi- } \\
\text { square }\end{array}$ & P Value \\
\hline A. Diagnosis & & & & & & & & & & \\
\hline Hypertension & 11 & 68.8 & 7 & 41.2 & 14 & 43.8 & 32 & 49.2 & 2.126 & 0.109 \\
\hline $\begin{array}{l}\text { Diabetes } \\
\text { Miletus }\end{array}$ & 5 & 31.2 & 10 & 58.8 & 18 & 56.2 & 33 & 50.8 & & \\
\hline B. $\begin{array}{l}\text { Duration } \\
\text { of illness }\end{array}$ & & & & & & & & & & \\
\hline 10 years & 7 & 43.8 & 6 & 35.3 & 24 & 75.0 & 37 & 56.9 & 4.344 & $0.028^{*}$ \\
\hline 20 years & 5 & 31.2 & 6 & 35.3 & 4 & 12.5 & 15 & 23.1 & & \\
\hline $\begin{array}{l}\text { More than } 20 \\
\text { years }\end{array}$ & 4 & 25.0 & 5 & 29.4 & 4 & 12.5 & 13 & 20.0 & & \\
\hline
\end{tabular}

* Significant $\mathbf{P} \leq \mathbf{0 . 0 5}$

\section{Discussion}

Pregnancy is a period of great joy, but also one of great stress to mother both physically and mentally. IN healthy women, pregnancy may increase many anxieties because of expected uncertainty associated with it. Evidences show that anxiety in pregnancy has adverse impact on the health of mother and labor outcomes such as preterm delivery, prolonged labor, caesarean birth, low birth weight (Madhavanprabhakaran, 2015). Moreover, chronic diseases can influence the course of pregnancy and may have lasting effects that manifest at and after birth. Therefore, it is not surprising that women with chronic diseases are often anxious about pregnancy (Kersten et al, 2014, Pinto, 2017).

The current study aims to describe pregnancy related anxiety among chronic ill women. In this regards, the current study revealed that, nearly half of the women experienced severe anxiety (Figure 1) this findings was supported by Madhavanprabhakaran (2015) who found that around three quarters of the women had moderate degree of anxiety, while around one third of them have severe degree, while Erkayaa et al (2017) stated that around two fifth of the studied women had mild anxiety levels and high anxiety levels, around one fifth had medium had high anxiety levels.

From the researcher point of view, these findings may be attributed to that nearly one third of the studied women in the current study aged 36 to 48 years old and this age group at higher risk for chronic health problems that plays an important role in raising anxiety level especially during pregnancy.

The current study documented that slightly more than half of the women have DM (Table:4). In contrast, Silva et al (2017) found that the main health problem reported by pregnant women although infrequently was systemic arterial hypertension. From the researcher point of view these findings shed the light on one of the major public health problem either nationally or internationally, since diabetes and especially gestational diabetes may play an active role in raising the prevalence of diabetes, that in turn affecting the community as a whole.

Furthermore, the current study goes in line with a systematic review written by Macaulay et al (2014) on Gestational Diabetes Mellitus in Africa which revealed that in 2013 around 19.8 million people were reportedly living with 
PREGNANCY RELATED TO ANXIETY AMONG etc ...

the diabetes in Africa and this number is predicted to increase to 41.5 million in 2035 equating to a $109 \%$ increase.

From the researcher point of view, the explosion in the prevalence of diabetes undoubtedly represents a serious public health burden. The risk is increased with the longer duration of the disease exposure. In this regards the current study reflect that more than half of the studied women reported that they suffering from the chronic illness since 10 years, and around one fifth of them reported that they suffer from chronic illness since 20 years and more (Table:4).

From the researcher point of view, an integrated activity to fight diabetes and gestational diabetes is highly important. In Egypt the actions plan targeting diabetes, Gestational Diabetes Care in Upper Egypt: project (2014-2017) was striving to improve detection and treatment of GDM and reducing the future risk of diabetes in the mother and offspring in Upper Egypt cities (Eltoony, 2017).

About $80 \%$ of mothers express anxiety and worry about their pregnancy or upcoming childbirth that was reported by Rondung et al (2016) and Erkayaa et al (2017). This findings confirm the current study findings which presents that, more than two fifth of the studied women reported that they are afraid of giving birth (Figure: 2). These findings may be attributed to poor education among the studied women where around one fifth of the studied women was illiterate or only has basic education (Table: 2 ).

Parents who expected to have a handicapped child are always bearing a load of stress (Feizi, 2014). In the current study more than half of the women are severely worries about bearing handicapped child (Figure: 3). This findings may be attributed to the age of the studied women, where nearly one third of the studied women in the current study aged 36 to 48 years old. American

Collage of Obstetrician and

Gynecologist (2017) declared that pregnancy after age 35 years is high risk pregnancy . Also, having a child later in life has certain risks; these risks have adverse impact on woman's health as well as her baby's health. All of these variables lead to anxiety and stress among the expectant mothers.

A woman's body undergoes many transformations during the nine months of pregnancy. Some are well known; others may catch her by surprise (Nierenberg, 2015). This fact goes in line with the current study findings where more than two fifths of the women severely concerned by their own appearance (Figure: 4). From the researcher point of view, this findings may be attributed to the number of pregnancy of the studied women, where more than one quarter of the studied women have double fetus (Table: 3). That leads to expectation of more changes of body image or appearance.

The current study reflects that there is a strong relation between the Anxiety level according to PRAQ-R2 and its three subdomains; fear of giving birth, worries about bearing a handicapped child and concern about own appearance (Table: 1). These findings were supported by Huizink et al (2016) they stated anxiety in pregnancy are common and the mothers worry about the labor and pain, also referred to as fear of childbirth, or they may be concerned about the health of the child they are carrying or the physical changes they experience. And there is a significant relation between the anxiety level and PRAQ-R2 constructs.

Huizink et al (2017) entitled "From prenatal anxiety to parenting stress: a longitudinal study" revealed that there is a significant relation between anxiety level and parents education. This finding goes in line with the current study findings where 
there is a highly significant relation between the anxiety level according to PRAQ-R2 and level of education of the women. Whereas, there is no significant relation observed between anxieties level according to PRAQ-R2 and women's age (Table: 2). In contrast Huizink et al (2017) study confirms that there is a significant relation between parent's age and anxiety level.

From the researcher point of view these findings may be attributed to that younger age women have low risk of chronic diseases compared to those who older and have a greater risk for developing chronic diseases. Moreover, women age plays a positive role in their preparation for parents role, where they always expecting pregnancy and use health services for follow-up, in contrast older women may get un planned pregnancy which in turn affecting their acceptance of the pregnancy and raise the anxiety level.

The current study presents that there were highly significant relation between the anxiety level according to PRAQ-R2 and gestational age. Whereas, there is no significant relation observed between anxiety level according to PRAQR2 and number of fetus (Table: 3) these findings confirmed by a study for anxiety, depression and stress in pregnancy implications for mothers, children, research, and practice which done by Schetter and Tanner (2012).

Additionally, the point of view of the researcher agrees with the fact that the level of anxiety affected by the pregnancy progress and varied according the pregnancy trimester. Hence, a woman who goes toward delivery in third trimester feels anxious due to their fear of getting complication or pass through difficult labor. Every pregnancy considered valuable for the mother either single or multiple fetus.
The current study presents that there is a significant relation observed between anxiety level according to PRAQR2 and women's duration of illness (Table: 4). These findings agree with the fact that, chronically or severely anxious mothers may feel overwhelmed and fatigued which might impact their diet and sleep habits and consistency of prenatal care (Shahhosseini et al, 2015). So every expectant mother suffering from chronic disease must be planned to accept that they may have extra anxiety level. Maternitynurse must encourage the pregnant women to try to find out what works for them and to regularly give themselves time to wind down (Haddad et al, 2011).

V. Conclusion

This study concluded that:

Nearly half of the women experienced severe anxiety according to the total anxiety sum score either by old subscale (PRAQ-R) or new subscale (PRAQ-R2) scoring. more than two fifth of the studied women reported that they are afraid of giving birth with the same finding either by old subscale (PRAQ-R) or by new subscale (PRAQ-R2) findings. More than half of them were severely worries about bearing handicapped child, more than two fifths of them severely concerned by their own appearance.

Moreover, the findings of this study indicated that there were a highly significant relation between the anxiety level according to PRAQ-R2 and its three sub domains, number of children, level of education of the women, gestational age and women's duration of chronic illness.

\section{Recommendations}

Based on the findings of this study the following were recommended:

1. Simple handouts as booklets and brochures about chronic diseases and anxiety pattern should be developed and distributed at antenatal clinics. 
PREGNANCY RELATED TO ANXIETY AMONG etc...

2. Evidence-based anxiety and chronic disease care guidelines should be integrated in maternity courses curriculum for nursing students.

Further researches are proposed to

1. Evaluate the effect

complementary therapy protocol on the chronically ill pregnancy

3. Anxiety management enhancing outcomes. educational session should be applied at the maternity hospitals and centers.

2. Pattern of anxiety among mother with preterm babies: a retrospective study.

3. The relationship between women anxiety pattern and labor outcome.

4. The effect of applying Exercise program on level of anxiety and pregnancy outcomes 